\title{
Neutronics Modeling of the SPERT III E-Core Critical Experiments with MPACT and KENO
}

\author{
Liangzhi Cao ${ }^{\mathrm{a}, \mathrm{b},{ }^{*}}$, Andrew Gerlach ${ }^{\mathrm{b}}$, Yunlin $\mathrm{Xu}^{\mathrm{c}}$, Thomas Downar ${ }^{\mathrm{b}}$, John C. Lee ${ }^{\mathrm{b}}$ \\ ${ }^{a}$ School of Nuclear Science and Technology, Xi'an Jiaotong University, Xi'an, China \\ ${ }^{\mathrm{b}}$ Department of Nuclear Engineering and Radiological Science, University of Michigan, Ann \\ Arbor, MI, USA \\ ${ }^{\mathrm{c}}$ Argonne National Laboratory, Argonne IL, USA
}

\begin{abstract}
The Special Power Excursion Reactor Test (SPERT) III E-Core is a small experimental reactor having many of the general characteristics of a commercial light water power reactor except for a great geometric complexity and stronger heterogeneity. A detailed steady-state neutronics model for SPERT III E-Core was developed with the Monte Carlo code KENO and the deterministic 3D transport code MPACT. All components including fuel assemblies, control rods, transient rod, flux suppressors, grid spacers and dummy spacer assemblies were explicitly modeled. Calculations were performed for Cold Zero Power (CZP) and Hot Zero Power (HZP) critical conditions of the core. Numerical results indicate that both models were able to achieve very good agreement with experimental measurements for both eigenvalue and control rod worths, and good agreement was obtained with each other with respect to fission rate distributions.
\end{abstract}

\section{Introduction}

Three-dimensional, full core modeling with pin resolved detail is widely recognized as the future trend of advanced computational simulation of nuclear reactors. However, the verification and validation $(\mathrm{V} \& \mathrm{~V})$ of these methods face considerable challenges for the methods and models development mainly because of the lack of experimental data and the difficulty in modeling the detailed geometry.

The Special Power Excursion Reactor Test (SPERT) Project was established as part of the U. S. Atomic Energy Commission's reactor safety program in 1954, with the objective of providing experimental and theoretical investigations of the kinetic behavior and safety of nuclear reactors. The SPERT III pressurized water reactor (Durgone, 1965) was constructed as a part of this safety program to fulfill the need for a facility in which to conduct reactor kinetic behavior and safety investigations under operating conditions. The facility was designed and incorporated essential features typical of pressurized-water and boiling-water reactors. General objectives in the SPERT III facility design included: (a) to provide a facility in which reactor power excursion tests could be performed and experimental information gathered on the kinetic behavior of the reactor, (b) to incorporate in the design a complete reactor and coolant system typical of existing and proposed pressurized water power reactors to permit an investigation of safety problems common to this class of reactors, and (c) to incorporate sufficient flexibility in the overall design to permit studies on several core designs (Durgone, 1965). Among several core designs, the E-Core consisting of 60 assemblies was employed to perform several reactivity insertion accident (RIA) experiments. The 
data measured during the experiments was available to validate neutronics codes for both steady-state and transient core conditions.

Several attempts have been made to simulate the SPERT III E-Core in recent years, to include CASMO/SIMULATE-3K of Studsvik Scandpower Inc. (Grandi and Moberg, 2012; Grandi, 2014), EUREKA-ATR of Japanese Atomic Energy Agency (Kosaka et al., 1988) GALAXY/COSMO-K of Mitsubishi Heavy Industry (Yamaji et. al., 2014), ANCK/MIDAC code of Westinghouse (Aoki et al., 2009), and MCNP/PARET of Argonne National Laboratory (ANL) (Olson, 2013). The focus of most of this work has been on the simulation of the transient behavior of the core and the steady-state experiments have not received as much attention during the past several years. Reasonably good agreement has been observed for many of the transient solutions, but the results for the steady-state simulations have not been as satisfying. CASMO5/SIMULATE-3K was validated against SPERT III E-Core at cold startup measurements (Grandi and Moberg, 2012) and a considerable discrepancy was observed in the critical control rod position at cold zero power (CZP) conditions. The measured critical control rod was $36.8 \mathrm{~cm}$ while the calculated value was $30.1 \mathrm{~cm}$ which corresponds to a discrepancy of about $2800 \mathrm{pcm}$ in reactivity. PARCS (Wang et al., 2013) was also validated against SPERT III E-Core with the homogenized cross-sections generated by SCALE/TRITON. Both of these codes are based on the nodal method and therefore encountered some limitations in explicitly modelling the complex geometry of the SPERT core. However, limitations were also observed in the MCNP simulation, which was used to explicitly model the detailed core geometry. The model developed by ANL (Olson, 2013) showed a discrepancy of about $\sim 1.3 \$$ in the reactivity.

The MPACT code is based on a 2D-1D transport solution and was originally developed by the University of Michigan to perform high-fidelity LWR analysis using whole-core transport calculations with neutron flux information provided at the sub-pin level (Kochunas, et al., 2013). KENO V.a is a three-dimensional Monte Carlo criticality transport program developed and maintained as part of the SCALE code package (Bowman, 2011). Both KENO and MPACT can explicitly model the complex geometry of SPERT-III E-Core core without homogenization. The principal motivation of this study was to establish a steady-state neuronics model for the SPERT III E-Core with a very detailed description of the geometry and composition. The objective was to compare the experimental measurements with both the deterministic code MPACT and the Monte Carlo code KENO, and to build confidence in the three-dimensional heterogeneous modeling of complex reactor designs.

This paper is organized as follows. Section 2 provides a detailed description of the SPERT III E-Core geometry and material compositions. Sections 3 and 4 are devoted to the MPACT and KENO models, respectively. In Section 5, numerical results of both codes are compared with measurements and the differences are analyzed. The final section provides a summary and conclusions.

\section{Core specifications}

The SPERT III E-core is a small, low-enriched $\mathrm{UO}_{2}$ fueled PWR. The core has the general 
neutronics characteristics of a commercial power reactor without a significant fission product inventory. The cross section of the core is illustrated in Fig. 1 and consists of 60 fuel assemblies, which are surrounded by different shapes of filler pieces and four rings of thermal shield, and housed by the reactor vessel. There are 48 fuel assemblies, each containing 25 fuel rods in a 5 by 5 rectangular array with a square pitch of $1.4859 \mathrm{~cm}$. There are 12 smaller fuel assembly cans 6.35 $\mathrm{cm}$ on a side, each containing 16 fuel rods arranged in a 4 by 4 rectangular array with the same pitch as the 25-rod assemblies. Four of the 16-rod assemblies surround the centrally located transient rod guide, and the remaining eight 16-rod assemblies form fuel followers of the eight E-core control rods. Four pairs of control rods and a cruciform-shaped transient rod are loaded in the core. The main design characteristics of the E-core are presented in Table 1. Other detailed core parameters can be found in the references of (Durgone, 1965; McCardell, et. al., 1969).

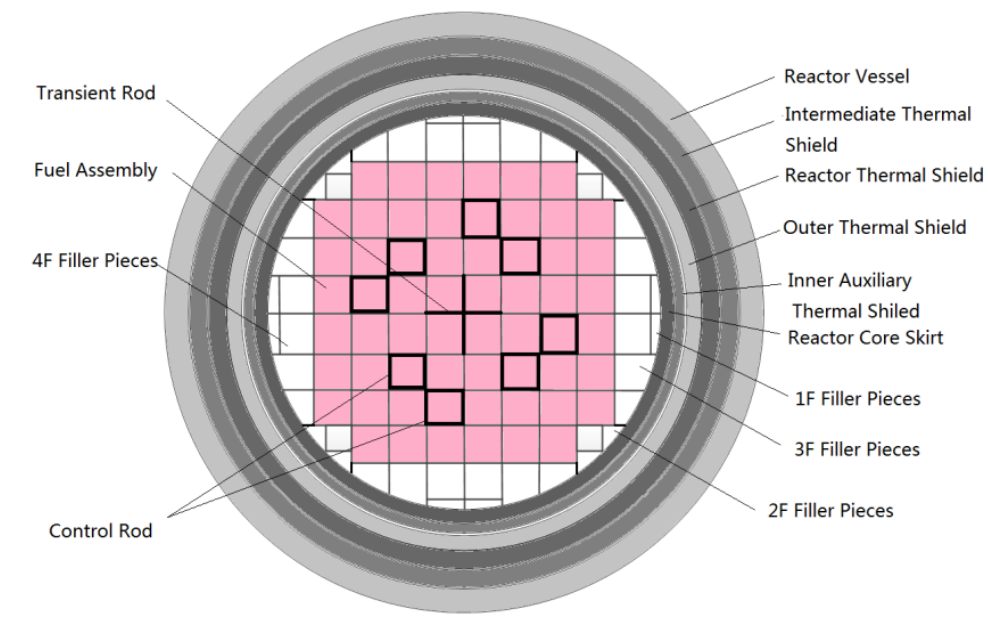

Fig. 1: SPERT III E-core cross-section.

The tubing and end plugs are composed of Types 348 and 347 stainless steel, respectively. The fuel is in the form of uranium dioxide pellets, $4.8 \mathrm{wt} \%$ enriched. Each of the fuel rods contains 38.5 grams of U-235 with an active fuel length of $97.282 \mathrm{~cm}$ which leaves a $6.35 \mathrm{~cm}$ expansion space at the top of the fuel rod. In this expansion space, a compression spring is positioned to keep the fuel pellets in place. The gas plenum includes 95 vol\% of helium to improve the heat transfer across the gap.

The 25 fuel rods are spaced in the fuel can by upper and lower fuel grids and two intermediate grids. The intermediate grids are spaced $33 \mathrm{~cm}$ and $67 \mathrm{~cm}$ above the lower fuel grid to minimize vibration and thermal bowing of the fuel rods. A total area of $774 \mathrm{~cm}^{2}$ in the form of slots has been removed from each stainless steel fuel can as shown in Fig. 2. These slots are so arranged that by proper orientation of the fuel assemblies, the slots in adjacent assemblies can be either aligned or blocked. The alignment of the slots allows core cross flow. The average heat transfer surface, based on the active fuel length, is $9045 \mathrm{~cm}^{2}$ per assembly, and the non-moderator-to-moderator ratio is 1.03 for a $7.62 \times 7.62 \mathrm{~cm}$ cell. 
Table 1: Basic Core / Fuel Data for SPERT III E-core

\begin{tabular}{ll}
\hline Parameters & Value \\
\hline Reactor type & Experimental PWR \\
Moderator/Coolant & $\mathrm{H}_{2} \mathrm{O} / \mathrm{H}_{2} \mathrm{O}$ \\
Core rated power & $20 \mathrm{MW}$ \\
Core equivalent diameter & $0.66 \mathrm{~m}$ \\
Active height & $97.282 \mathrm{~cm}$ \\
Fuel rod outer diameter & $1.1836 \mathrm{~cm}$ \\
Fuel rod inner diameter & $1.0820 \mathrm{~cm}$ \\
Fuel pellet diameter & $1.0668 \mathrm{~cm}$ \\
Fuel rod pitch & $1.4859 \mathrm{~cm}$ \\
Fuel enrichment & $4.8 \mathrm{wt} \%$ enriched UO $2\left(10.5 \mathrm{~g} / \mathrm{cm}^{3}\right)$ \\
Fuel tube & Stainless steel, type 348 \\
Gas gap & Helium \\
Control rods composition & Absorber section $1.35 \quad \mathrm{wt} \%{ }^{10} \mathrm{~B} \quad$ in Type $\quad 18-8$ \\
25-rod fuel assembly & stainless steel; $0.4724 \mathrm{~cm} \mathrm{thick} \mathrm{hollow} \mathrm{square} \mathrm{box}$ \\
16-rod fuel assembly & $7.5565 * 7.5565 * 130.175 \mathrm{~cm}$ \\
CR with fuel followers & $6.3398 * 6.3398 * 130.175 \mathrm{~cm}$ \\
Fuel assembly pitch & $6.2890 * 6.2890 * 112.673 \mathrm{~cm}$ \\
Filler pieces thickness & $7.62 \mathrm{~cm}$ \\
Assembly box thickness & $0.3175 \mathrm{~cm}$ \\
\hline & $0.3175 \mathrm{~cm}$ \\
\hline
\end{tabular}

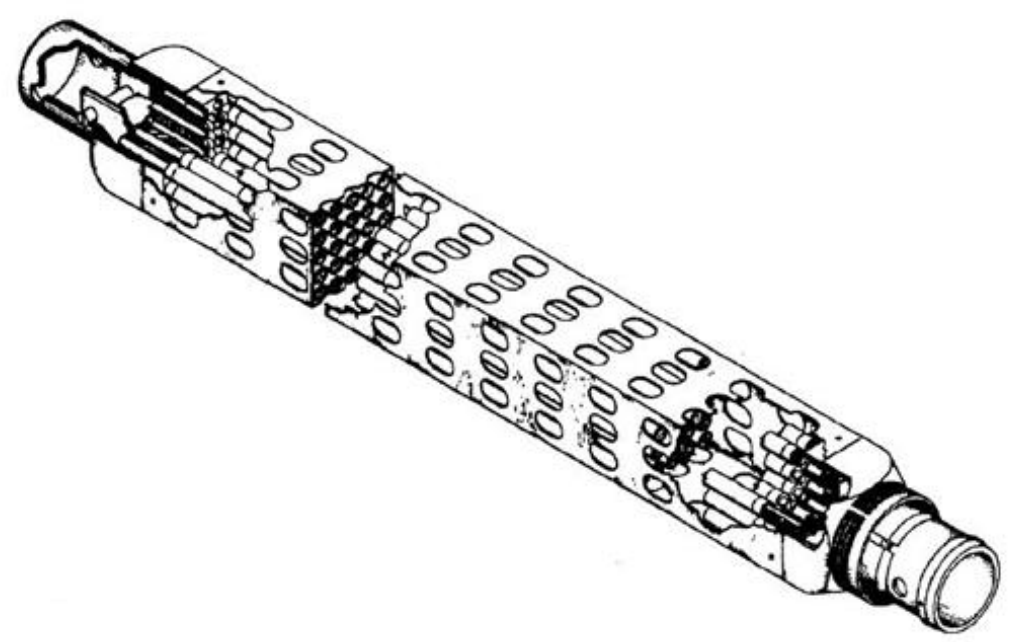

Fig. 2: 25-rod Fuel Assembly (Durgone, 1965)

There are eight control rods located in the core, two of which are provided in each quadrant. The two rods are joined by a yoke and driven by a single drive mechanism. The rods are the fuel-poison type, containing fuel in the lower section and a poison (neutron absorber) material in the upper section. A control rod assembly is shown in Fig. 3. 


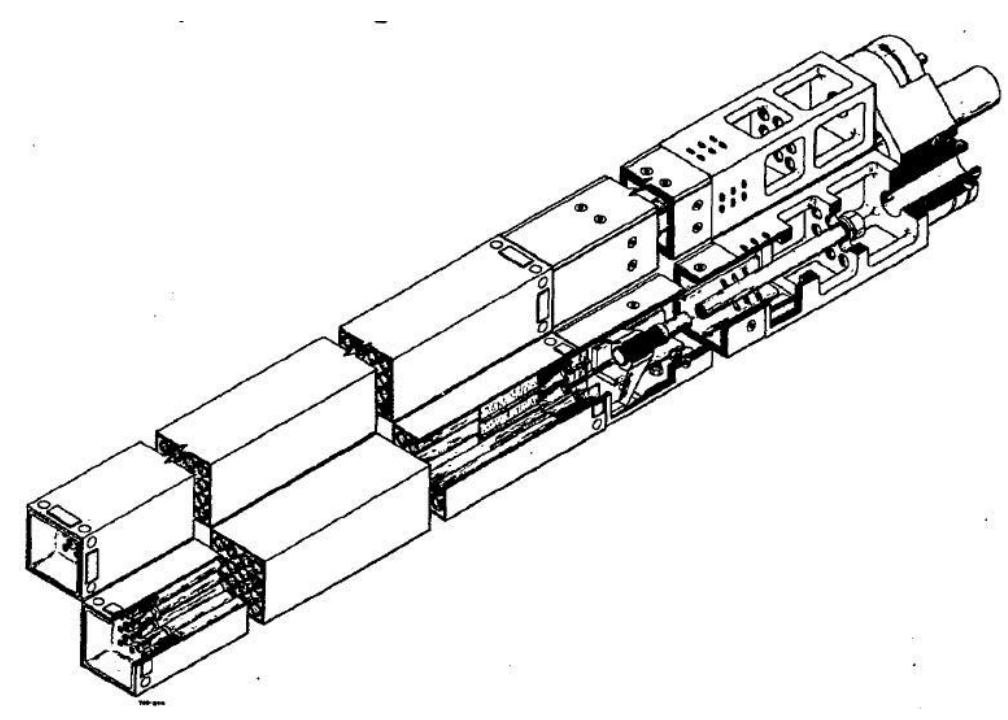

Fig. 3: Control Rod Assemblies on one Yoke (Durgone, 1965)

The fuel section of the control rod assemblies consists of 16 fuel rods containing a total of 616 grams of U-235. The fuel rods are the same as those used in the fuel assemblies. The average heat transfer area is $5787 \mathrm{~cm}^{2}$ per control rod. The poison section is a square box constructed of $0.47244 \mathrm{~cm}$ thick Type 18-8 stainless steel plate containing $1.35 \mathrm{wt} \% \mathrm{~B}-10$.

Flux suppressors are provided in the region between the end of the poison box and the top of the fuel rods. There are 12 suppressors in each control rod assembly with six of the suppressors being $5.55 \times 2.54 \times 0.0762 \mathrm{~cm}$ plates while the other six are $5.94 \times 6.90 \times 0.0762 \mathrm{~cm}$ plates. These suppressors are made of the same material (B-10 stainless steel alloy) as the poison section. However, there is no additional description on the structure of the flux suppressors.

The transient rod is a cruciform-shaped rod with blades, $13 \mathrm{~cm}$ wide and $0.476 \mathrm{~cm}$ thick. The upper section, which is normally in the core, is $142 \mathrm{~cm}$ long and constructed of 18-8 stainless steel. The lower section, which is the absorber section and normally extends below the core, is $96.52 \mathrm{~cm}$ long and constructed of 1.35 wt\% B-10 stainless steel. Haynes No. 40 alloy bushing pads, 11.75 $\mathrm{cm}$ square and $0.2286 \mathrm{~cm}$ thick, guide and position each blade in the transient rod guide. The yoke section, constructed of 347 stainless steel, is pinned to the upper section of the rod and forms the coupling between the transient rod and transient rod drive. See Fig. 4 for the transient rod assembly.

The 16-rod fuel assembly is similar to the 25-rod fuel assembly. The fuel rods and the fuel rod pitch are the same as the 25-rod fuel assembly. The average heat transfer surface is $5787 \mathrm{~cm}^{2}$ per assembly, and the nonmoderator-to-moderator ratio is 0.942 for the assembly. Since the core skirt is cylindrical, the space between the square fuel assembly positions and the cylindrical core skirt must be occupied by appropriately shaped filler pieces. Dummy spacer assemblies (filler pieces) of the shapes shown in Fig. 5 are therefore required to fill the lattice positions unoccupied by fuel assemblies in order to maintain hydraulic equilibrium for various core sizes. These assemblies are designated as Type $1 \mathrm{~F}, 2 \mathrm{~F}, 3 \mathrm{~F}$ and $4 \mathrm{~F}$ respectively according to the space requirement. The filler box is constructed of $0.3175 \mathrm{~cm}$ plate welded to the size and shape required. 


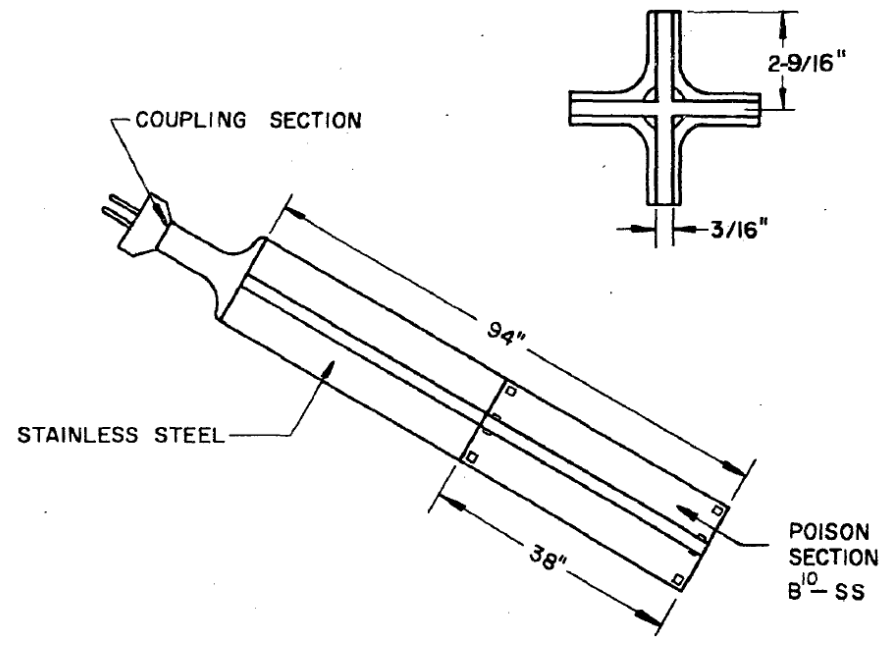

Fig. 4: Transient rod assembly (Durgone, 1965)
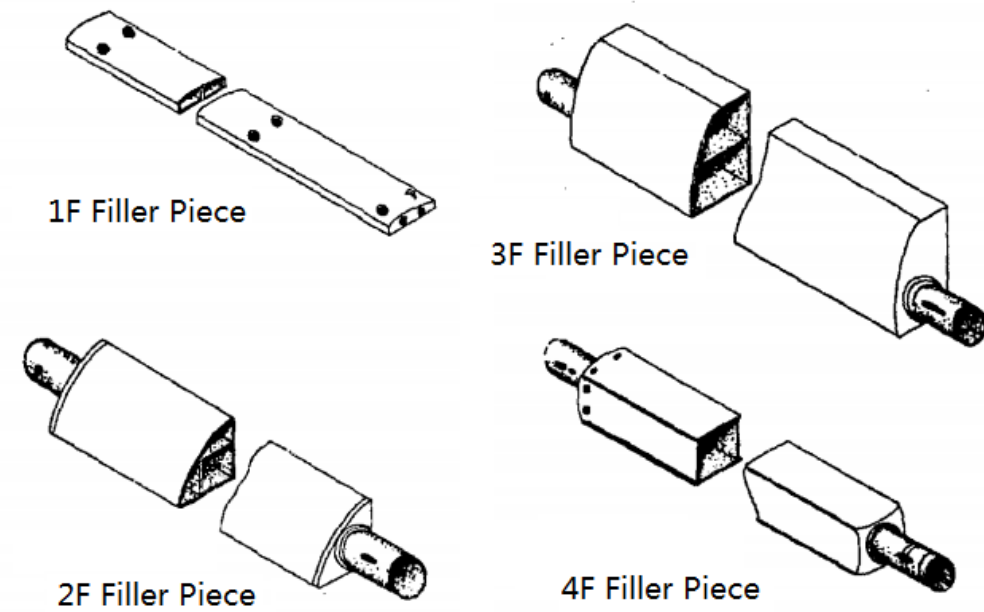

Fig. 5: Core Filler Pieces (Durgone, 1965)

\section{MPACT Model of SPERT III E-core}

\subsection{MPACT Overview}

The MPACT code consists of several libraries and transport solvers that provide the functionality necessary to solve steady-state eigenvalue and power distribution problems. The results given in this paper are calculated by using the 2D/1D coupling method where the radial flux is obtained by 2D Method of Characteristics (MOC) and the axial solver is the Nodal Expansion Method (NEM) for 1D diffusion equation. Coarse Mesh Finite Difference (CMFD) is utilized for computational speed-up. The subgroup method is chosen for the resonance self-shielding calculation, where the subgroup parameters are generated from ENDF-BVII.0 and the subgroup fixed-source-problem is solved by the MOC. (Y. Liu, et.al., 2013) 


\subsection{MPACT Fuel Pin Model}

The fuel pin is the basic unit of modeling in MPACT and the discretization used here is shown in Fig. 6. The fuel pins in the 25-rod assemblies and 16-rod assemblies have the same size and pin pitch but are offset by a half pitch. To meet the requirement of CMFD meshing, each fuel pin was subdivided into four quarter pins.

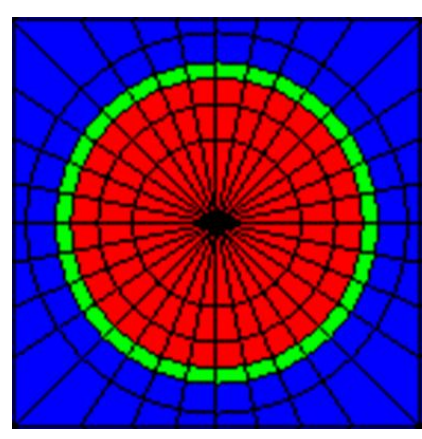

Fig. 6: MPACT model of fuel pin

Each quarter pin is a $0.74295 \mathrm{~cm}$ by $0.74295 \mathrm{~cm}$ square with 3 concentric arcs of material boundaries with the actual pin center at a corner of the "pin" mesh. The radius of the first (smallest) arc is $0.5334 \mathrm{~cm}$. The radius of the second arc is $0.59182 \mathrm{~cm}$; the material between first and second arcs is a mixture of $87.545 \mathrm{vol} \%$ type 348 stainless steel and $12.455 \mathrm{vol} \%$ of helium. The material outside of the second arc is all coolant. The coolant is water with varied temperature depending on the particular experiment. The third arc is added within the coolant region for improving discretization.

\subsection{MPACT $5 \times 5$ Assembly Model}

The 25-rod assembly is modeled as shown in Fig. 7. The inner part of the 25-rod assembly model consists of $10 \times 10$ quarter fuel pins. This array is surrounded by a $0.0635 \mathrm{~cm}$ thick can and $0.03175 \mathrm{~cm}$ of bypass water outside the can. The can and bypass water together form one layer of MPACT pins. Therefore, the 25-rod assembly is divided into a $12 \times 12$ array of pin mesh with the thicknesses of the inner pin mesh of $0.74295 \mathrm{~cm}$, and thicknesses of the outer pin mesh of 0.09525 $\mathrm{cm}$. This meshing was also used for all other assembly models.

The bypass gap is unheated water with the temperature and density varying depending on the particular experiment. The can consists of a mixture of $75 \mathrm{vol} \%$ stainless steel and $25 \mathrm{vol} \%$ unheated water, which represents the $774 \mathrm{~cm}^{2}$ of slots that have been removed from each stainless steel fuel can. 


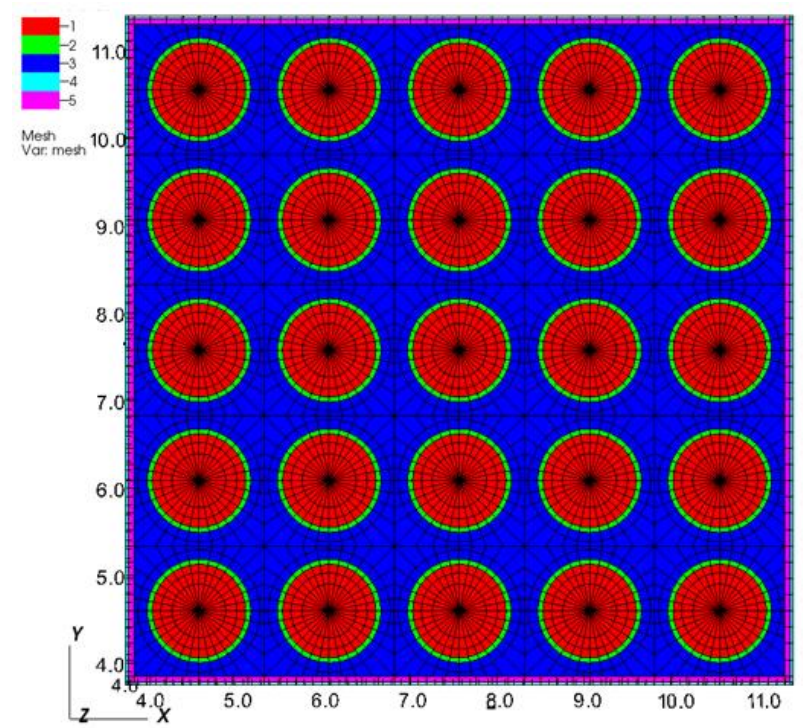

Fig. 7: MPACT model of 25-rod assembly

\subsection{MPACT Control Rod Model}

The top part (absorber) of the control rod is modeled as shown in Fig. 8. The outer dimension of the absorber is $6.28904 \mathrm{~cm}$ by $6.28904 \mathrm{~cm}$ with a thickness of $0.47244 \mathrm{~cm}$. The absorber is divided into two rings of MPACT pin mesh to match the meshing with the 25-rod assembly. The thickness of the absorber in the outer ring of pin mesh is $0.19812 \mathrm{~cm}$, while the thickness of absorber in the inner ring of pin mesh is $0.27432 \mathrm{~cm}$.

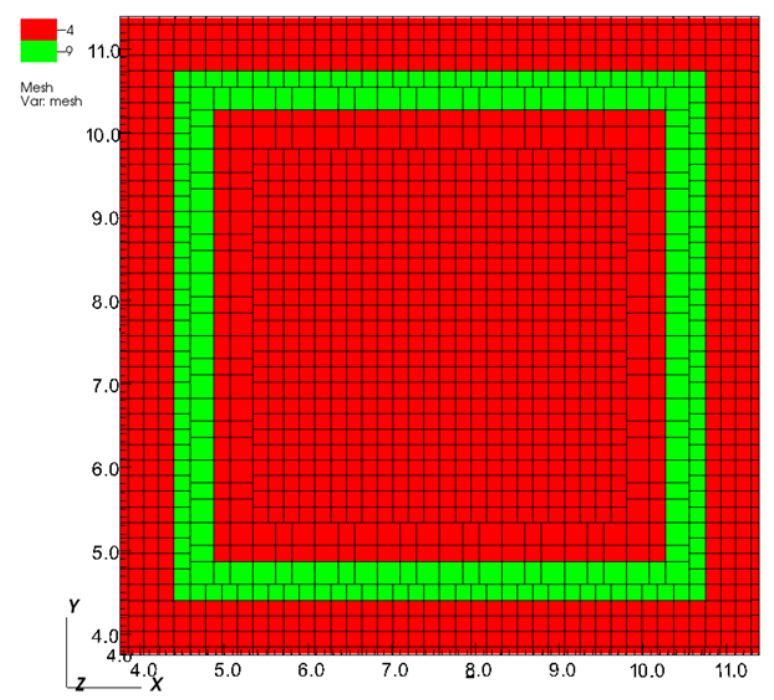

Fig. 8: MPACT model of control rod

The control rod absorber consists of type 18-8 stainless steel plates containing $1.35 \mathrm{wt} \%$ B-10. The remaining material in the control rod model (both inside and outside the absorber) is unheated water. 
The control rod follower is modeled as shown in Fig. 9. There is an $8 \times 8$ array of quarter pins at the center of the assembly that is surrounded by the can for the follower and is located within the ring of pin mesh surrounding the fuel pins. The thickness of the can is $0.1837 \mathrm{~cm}$, which is calculated from $18 \mathrm{~cm}^{2}$ of the flow area. There is a $0.01442 \mathrm{~cm}$ gap between the can and the $8 \times 8$ array of quarter pins.

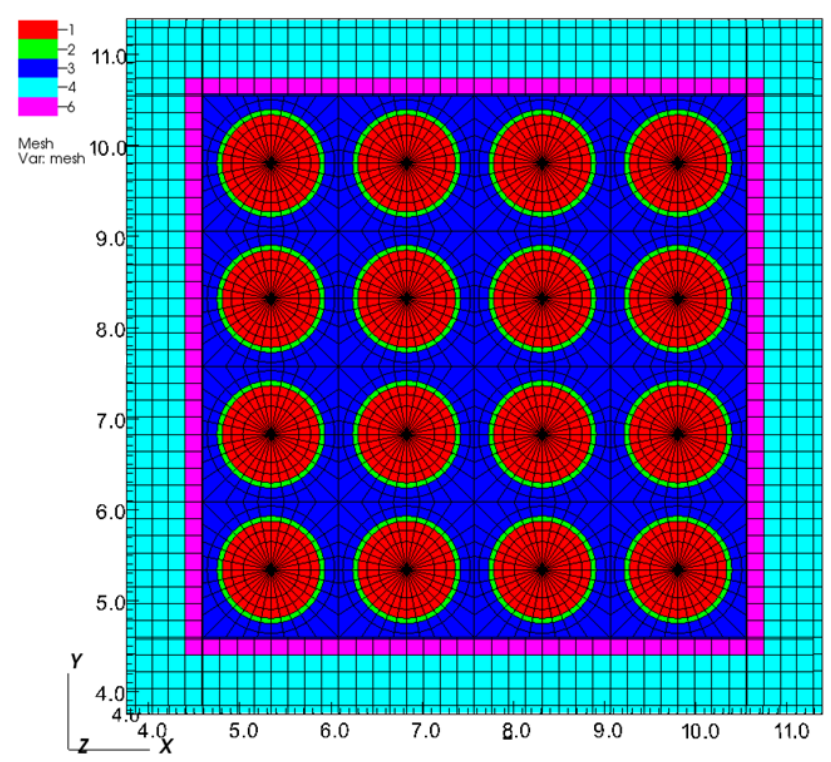

Fig. 9: MPACT model of control rod follower

The can consists of stainless steel, and the material in the gap between the can and the $8 \times 8$ array of quarter pins is water, while the material outside of the can is unheated water.

\subsection{MPACT Model for $4 \times 4$ Assembly with Transient Rod}

The 16-rod assembly is surrounded by one quarter of the cruciform transient rod on two sides as shown in Fig. 10. There is an $8 \times 8$ array of quarter pins at the center of the assembly, which is identical to the control rod follower. Also similar to the control rod follower, the can is located within the ring of pin mesh surrounding the fuel pins. The thickness of the can is $0.0635 \mathrm{~cm}$, which is calculated from the $20 \mathrm{~cm}^{2}$ of flow area and a non-moderator to moderator ratio of 0.942 . There is a $0.10922 \mathrm{~cm}$ gap between the can and the $8 \times 8$ array of quarter pins. There is a transient rod blade in one corner of the assembly extending along two sides. The thickness of the blade in the model is $0.238125 \mathrm{~cm}$, corresponding to half of the thickness of the cruciform-shaped transient rod blades. The thickness of the peripheral cell is $0.09525 \mathrm{~cm}$ and the rest of the transient blade with a thickness of $0.142875 \mathrm{~cm}$ is located in the second outer ring of pin mesh together with the can. 


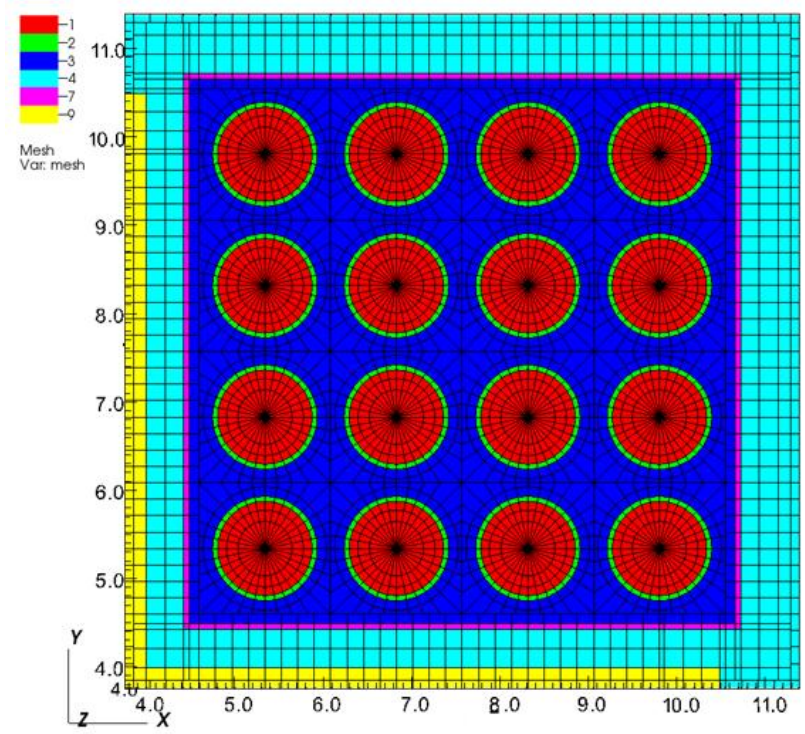

Fig. 10: MPACT model of 16-rod assembly with cruciform transient rod

The can is composed of stainless steel, and the transient blade is composed of type 18-8 stainless steel plate containing $1.35 \mathrm{wt} \% \mathrm{~B}-10$. The material in the gap between the can and the $8 \times 8$ array of quarter pins is heated water, while the material outside the can is unheated water. When the control blade is withdrawn, the model is the same as shown in Fig. 10 except the control blade material is replaced by stainless steel without boron. There are three other quarters of the transient rod surrounding the 16-rod assemblies that are identical to those shown in Fig. 10 except that they are rotated as shown.

\subsection{MPACT Ancillary Components Model}

The core filler pieces are explicitly modeled in MPACT as shown in Fig. 11. The thickness of the filler box is $0.3175 \mathrm{~cm}$ and the outer dimension is the same as the 25-rod fuel assembly. The curved portion of type $1 \mathrm{~F}, 2 \mathrm{~F}$ and $3 \mathrm{~F}$ are approximated on the rectangular grid.

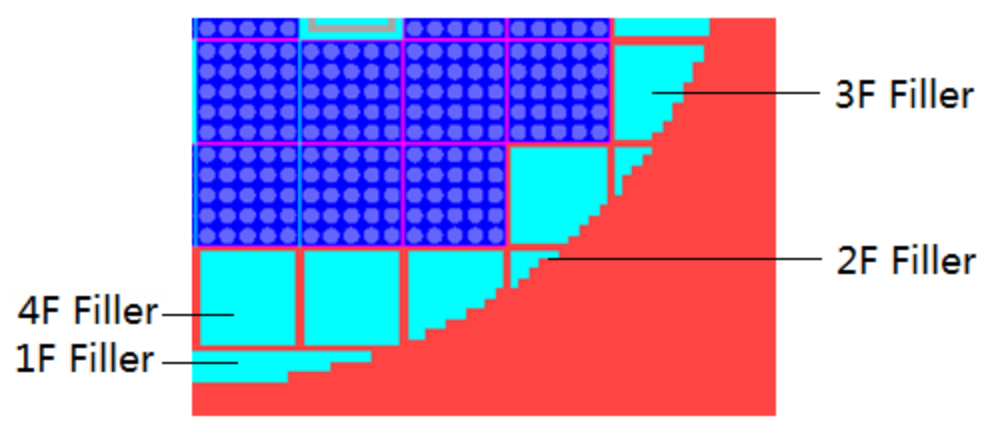

Fig. 11: MPACT model for core filler

The weight of the intermediate grids is not provided in the documentation and was estimated to be 300 grams. Because the structure of the grid is too complex to model explicitly, it is homogenized with the coolant in a height of approximately $6 \mathrm{~cm}$ (one axial mesh). The corresponding composition of the grid is $19 \%$ steel and $81 \%$ water. The positions of the two axial grids are in the 
6th and the 12th node from the bottom of the active core as shown in Fig. 12.

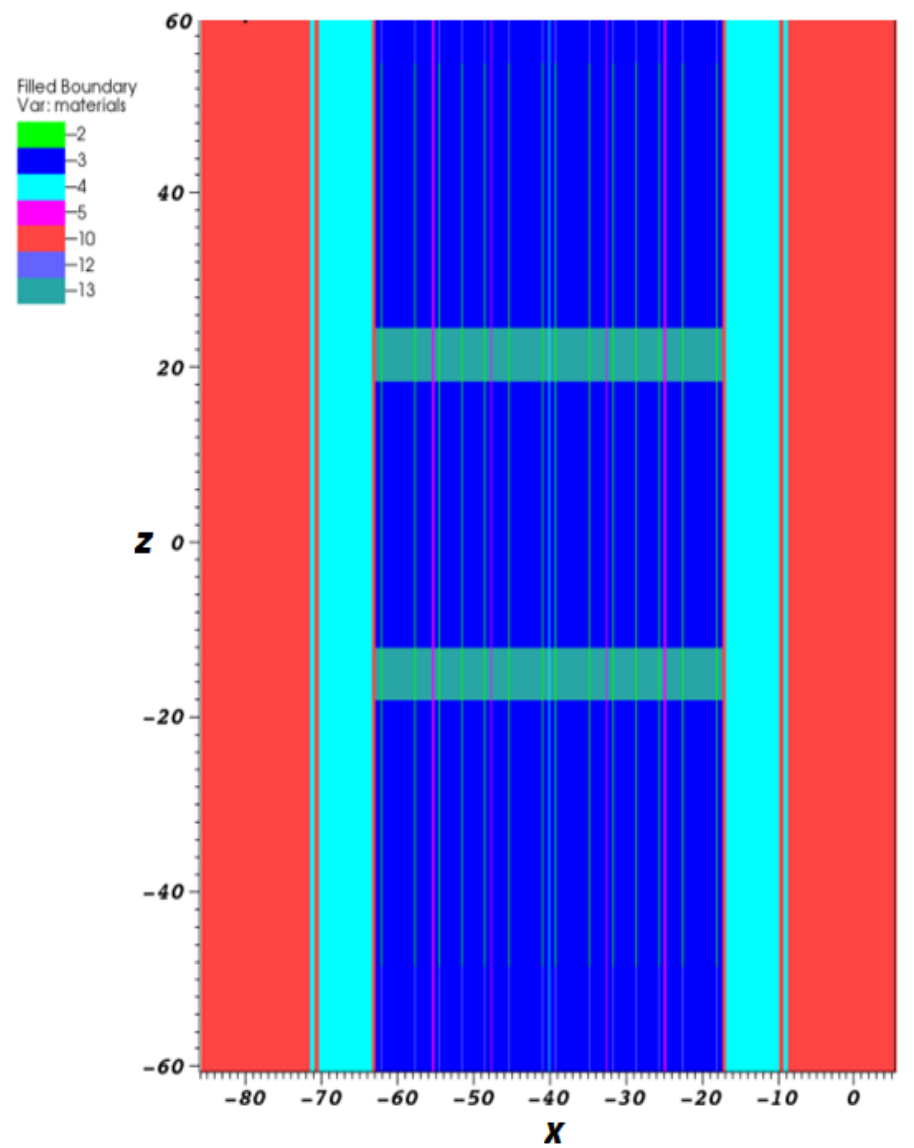

Fig. 12: MPACT model for axial grids

The flux suppressors between the control rod absorbers and fuel followers were modeled explicitly. According to the documentation, the distance between the absorber and fuel follower is $11.938 \mathrm{~cm}$, so the lower half of that height is filled with spring like the other fuel rods, while the upper half is filled with moderator and type 18-8 stainless steel containing $1.35 \mathrm{wt} \% \mathrm{~B}-10$. While the precise geometry of the flux suppressor was not available, the volume of steel containing B-10 was preserved with the data given in the documentation. The flux suppressors were modeled as shown in Fig. 13.

\subsection{MPACT Full Core Model Overview}

The MPACT model for the bottom of the active core is shown in Fig. 14. In this section, the transient rod consists of the absorber region and the control rods consist of the fuel follower sections. The reactor vessel, thermal shield, and reactor core skirt are modeled with homogenous stainless steel with an inner diameter of $76.2 \mathrm{~cm}$. 


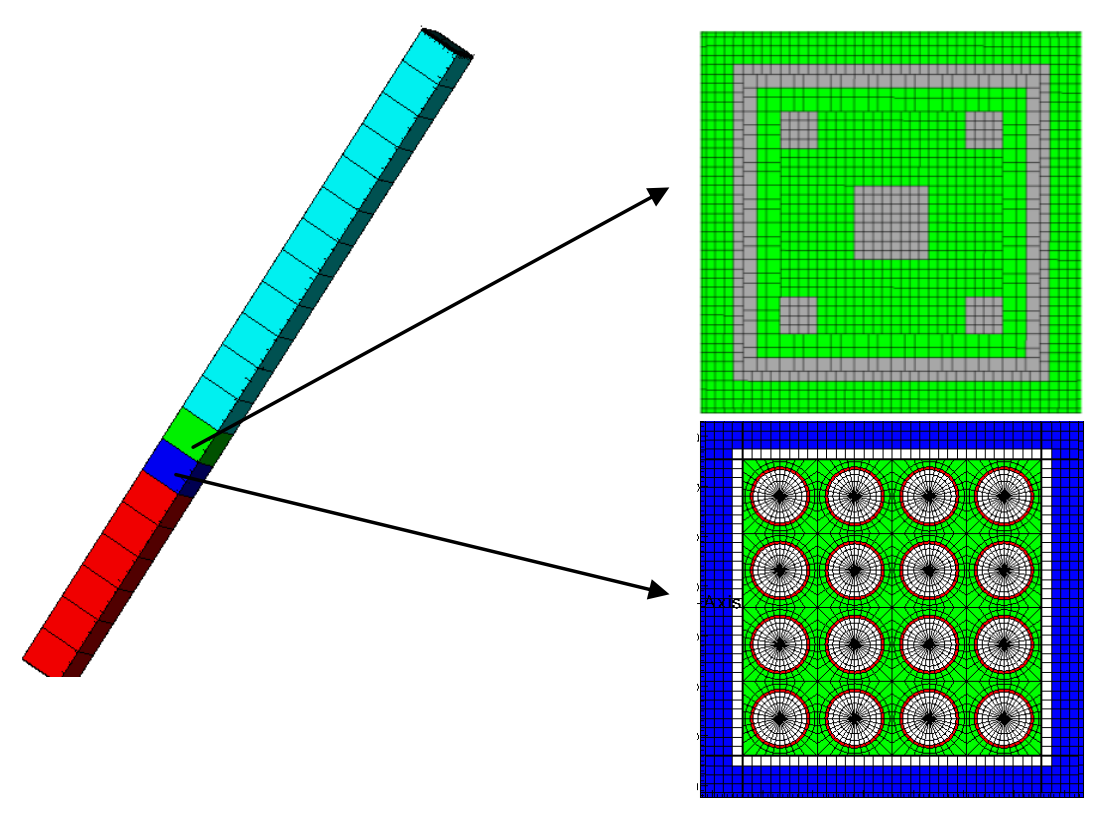

Fig. 13: MPACT model for flux suppressors

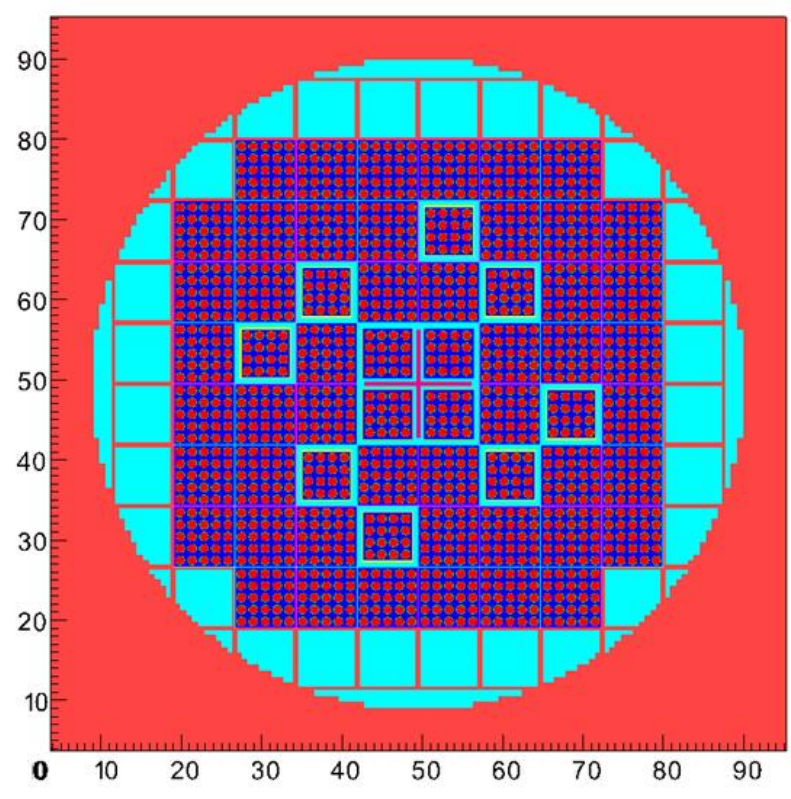

Fig. 14: MPACT model for bottom of active core

The MPACT model for the flux suppressor region at a location in the middle of the active core is shown in Fig. 15. In this section, the transient rod consists of the non-absorber stainless steel section and the flux suppressors are clearly visible in the control rods. One of the two axial grids happens to be contained in the moderator as well. 


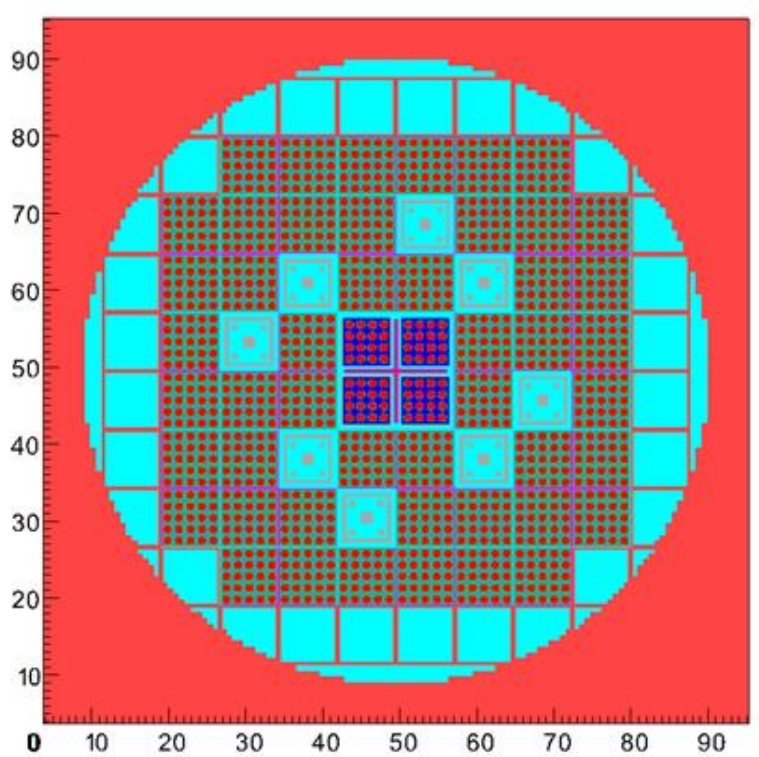

Fig. 15: MPACT model for middle of active core

The MPACT model for the top of active core is shown in Fig. 16. In this section, the transient rod consists of the non-absorber stainless steel section and the control rods consist of the absorber sections.

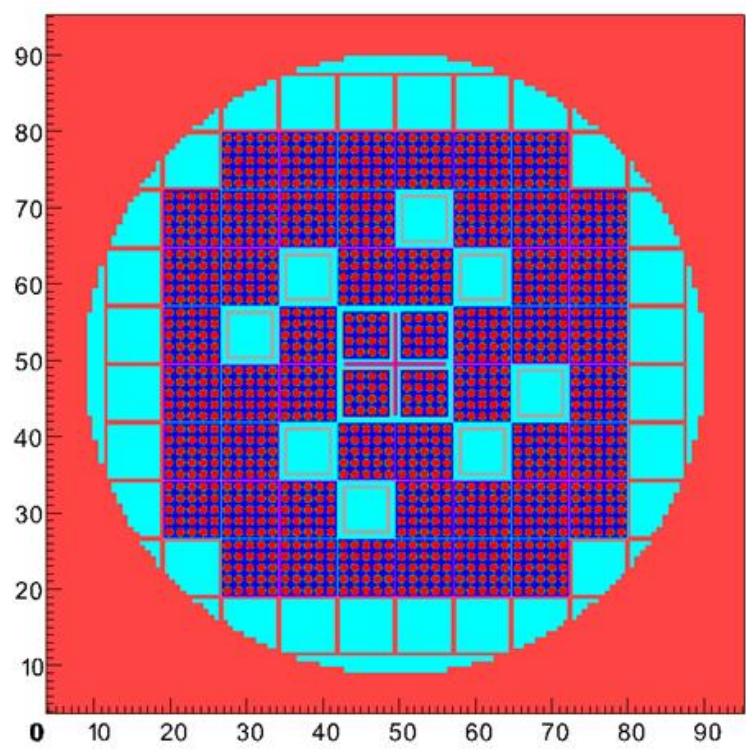

Fig. 16: MPACT model for top of active core

The MPACT model for the bottom reflector is shown in Fig. 17. In this section, the transient rod consists of the absorber region and the control rods consist of the fuel follower sections. The 16-rod transient assemblies and 25-rod assemblies are below the active fuel level and modeled as stainless steel end plugs in this section. 


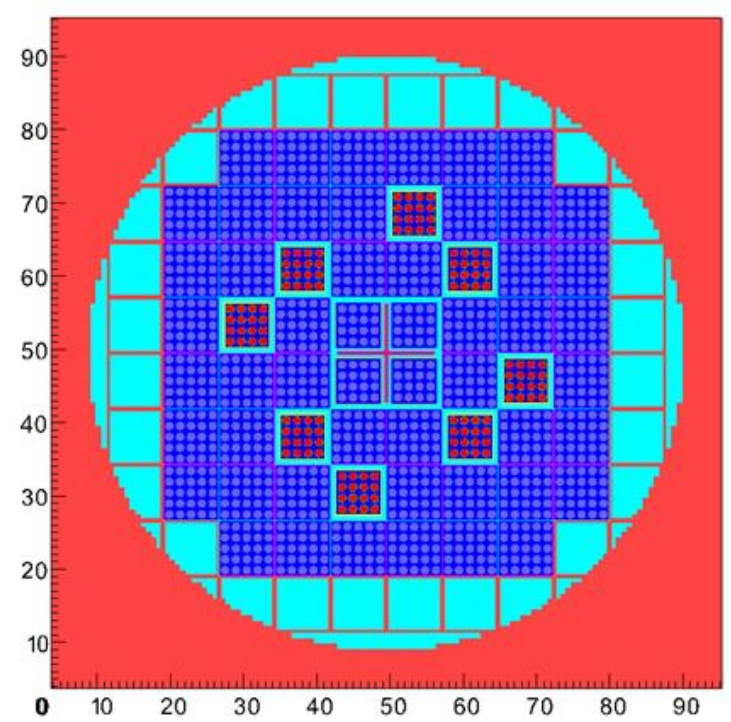

Fig. 17: MPACT model for bottom reflector

The MPACT model for lower plane of the top reflector is shown in Fig. 18. In this section, the transient rod consists of the non-absorber stainless steel section and the control rods consist of the absorber sections. The 16-rod transient assemblies and 25-rod assemblies are above the active fuel level and modeled as expansion-space stainless steel compression springs occupying $5 \%$ of the space in this section.

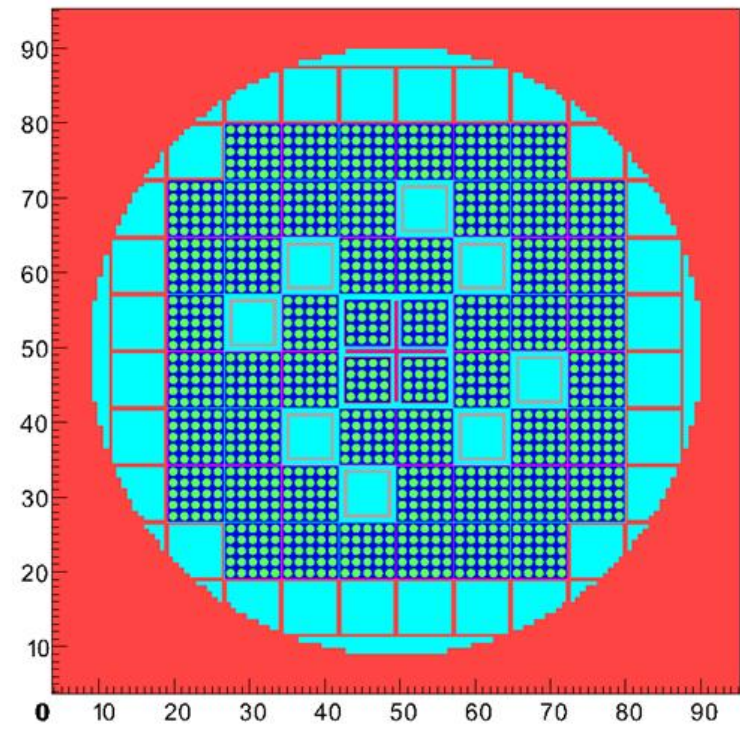

Fig. 18: MPACT model for lower plane of top reflector

The MPACT model for the upper plane of top reflector is shown in Fig. 19. In this section, the transient rod consists of the non-absorber region and the control rods consist of the absorber sections. The 16-rod transient assemblies and 25-rod assemblies are above the active fuel level and modeled as stainless steel end plugs in this section. 


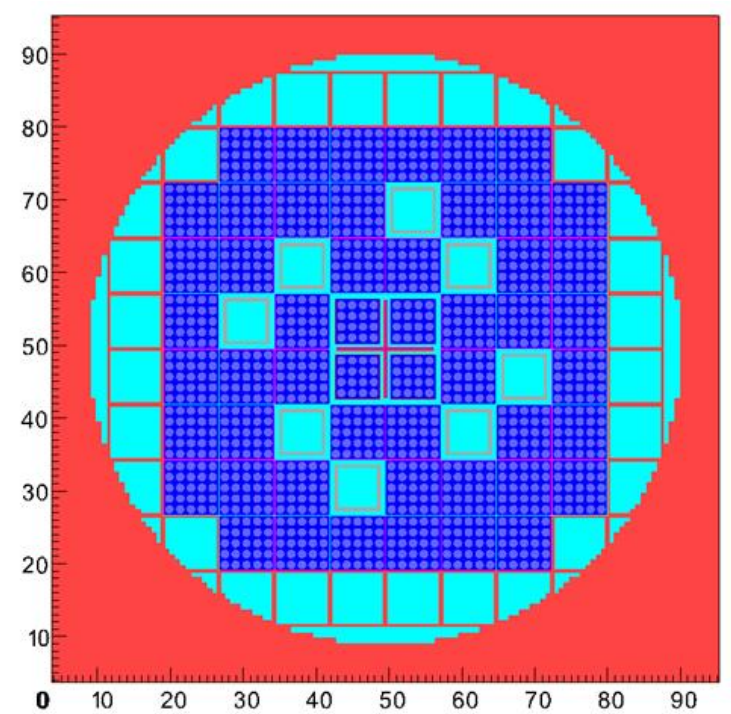

Fig. 19: MPACT model for upper planes of top reflector

The thicknesses of axial meshes are selected to exactly model the control rod and transient position. Generally, the whole model includes 2 axial meshes for the lower reflector, 2 axial meshes for the upper reflector, and 16 axial meshes for the active core. The specific thickness for each plane is determined by the control rod position. A typical thickness is around $6 \mathrm{~cm}$.

\section{KENO Model of SPERT III E-core}

The KENO model was developed to mimic exactly the geometry of the MPACT model. There are only three differences between the KENO and MPACT models: 1) the reactor containment vessel is explicitly modeled as a cylinder in KENO, rather than approximated on a rectangular grid as in the MPACT model; 2) the filler pieces do not closely contact the reactor skirt to avoid overlapping geometry and 3) a small gap $\left(10^{-5} \mathrm{~cm}\right)$ is introduced between assemblies in the KENO model to ensure that boundaries of "holes" (assemblies) do not overlap. These minor discrepancies should have a negligible effect on the results of the simulations. The KENO simulations were run in continuous energy mode with 5,500 generations consisting of $5 \times 10^{6}$ neutrons per generation, of which 500 generations were skipped.

In order to calculate pin powers throughout the core, a separate unit for each region of interest was created. KENO does provide mesh tally capabilities, but only the flux can be tallied and not reaction rates. KENO does not have the ability to explicitly calculate pin powers, and therefore fission rates were calculated instead.

Figure 20 includes depictions of the KENO model taken at the same axial plane as Fig. 14 through Fig. 19 of the MPACT model. Additionally, Fig. 21 shows a vertical slice through the core, which provides a useful perspective on the axial variation. 


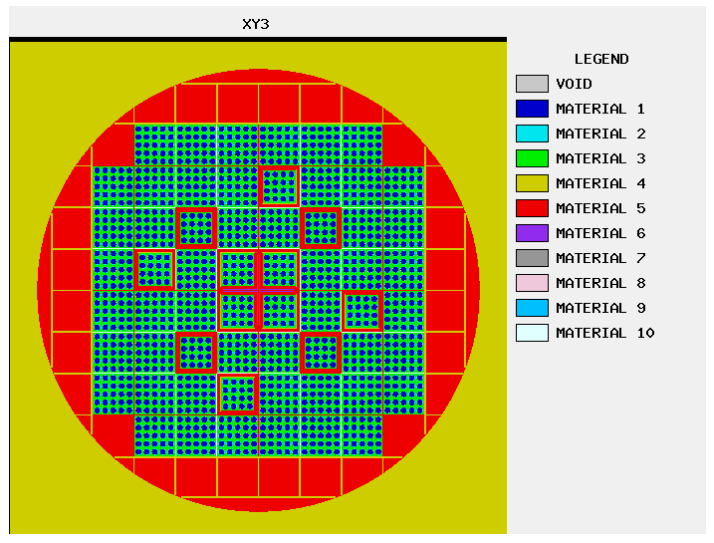

(a) bottom of active core

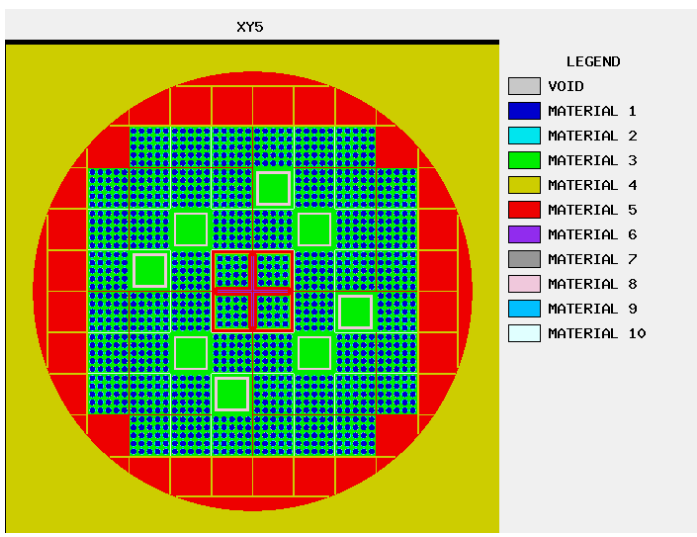

(c) top of active core

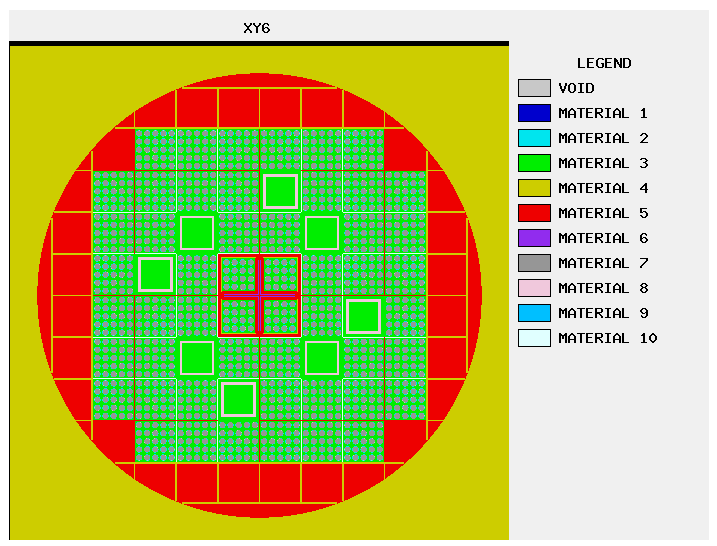

(e) lower plane of top reflector

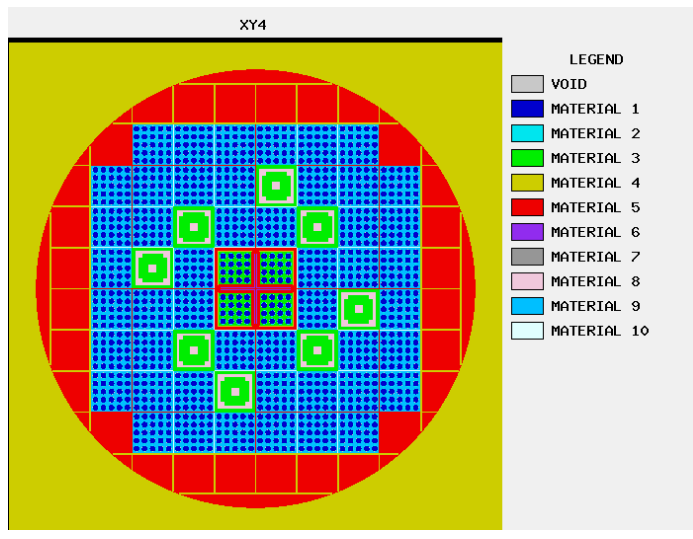

(b) middle of active core

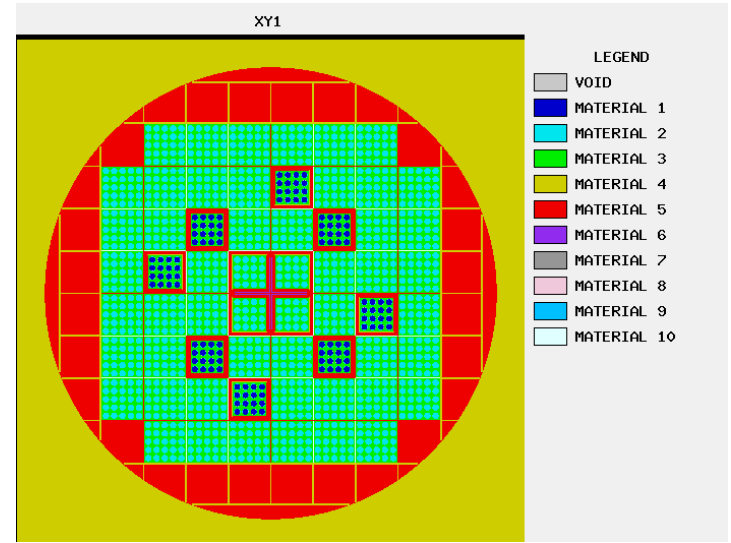

(d) bottom reflector

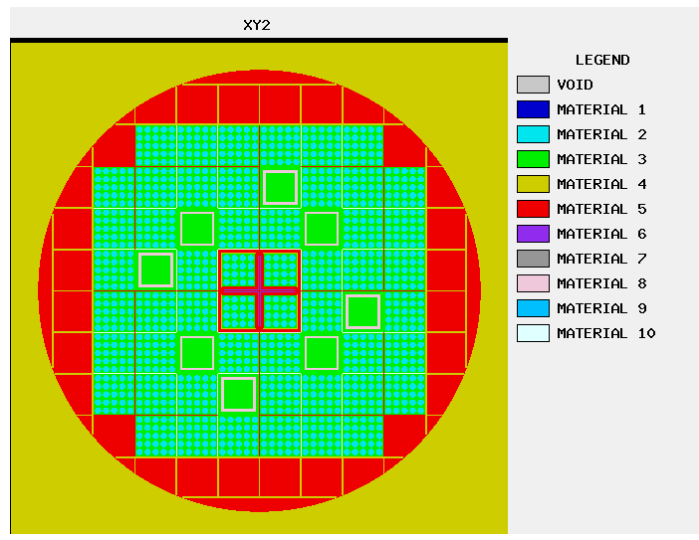

(f) upper planes of top reflector

Fig. 20: KENO model for SPERT core 


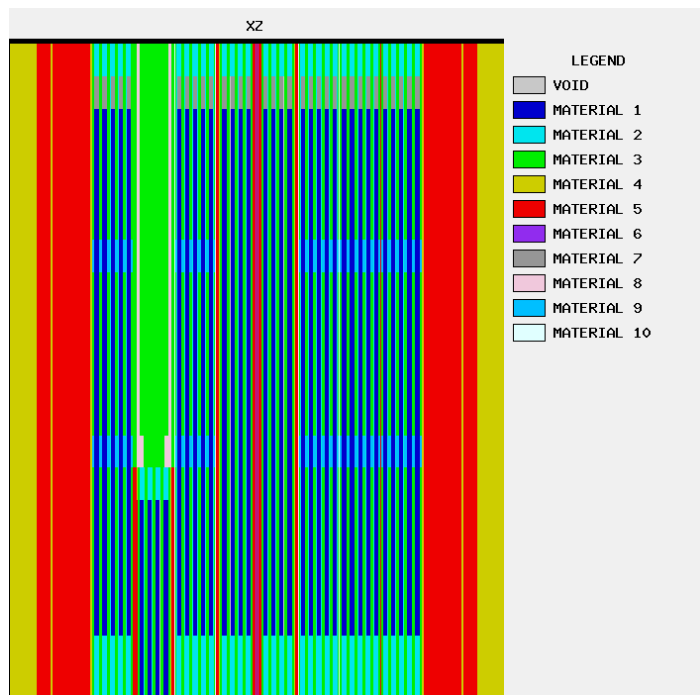

Fig. 21: Vertical slice of the KENO model

\section{MPACT and KENO Results and Analysis}

The eigenvalue and critical control rod positions for the cold zero power (CZP) and hot zero power (HZP) configurations of the SPERT III E-core were calculated with MPACT and KENO. The cases were performed in MPACT using P2 scattering with $0.05 \mathrm{~cm}$ ray spacing, and the Chebyshev-Gauss quadrature set and 16 azimuthal and 4 polar angles per octant. The multi-group NEM kernel was used to perform the axial solution, and both CZP and HZP cases were run with 20 axial planes. Solutions were performed with the ORNL 47-group library based on ENDF-VII. The typical computational time for each case running with 720 cores is around 2 hours. The KENO cases were run with the continuous energy (CE) ENDF-VII library. The computational time of KENO with 240 cores for each case is around 150 hours. The eigenvalues for MPACT and KENO are compared in Table 2. The critical control rod positions are also compared with experiment in Table 3; however, only the CZP critical control rod position was calculated with KENO.

Table 2: Comparison of eigenvalues

\begin{tabular}{ccccc}
\hline Case & $\begin{array}{c}\text { Temp. } \\
(\mathrm{F})\end{array}$ & $\begin{array}{c}\text { C.R. Position } \\
(\mathrm{cm})\end{array}$ & MPACT & KENO \\
\hline CZP & 70 & 37.0 & 0.99613 & $0.99857 \pm 0.00001$ \\
HZP & 550 & 71.8 & 1.00023 & $1.00069 \pm 0.00001$ \\
\hline
\end{tabular}

Table 3: Comparison of critical control rod positions

\begin{tabular}{lcccc}
\hline Case & $\begin{array}{c}\text { Temp. } \\
(\mathrm{F})\end{array}$ & $\begin{array}{c}\text { Experiment } \\
(\mathrm{cm})\end{array}$ & $\begin{array}{c}\text { MPACT } \\
(\mathrm{cm})\end{array}$ & $\begin{array}{c}\text { KENO } \\
(\mathrm{cm})\end{array}$ \\
\hline CZP & 70 & 37.0 & 38.2 & 36.3 \\
HZP & 550 & 71.8 & 74.4 & - \\
\hline
\end{tabular}

As indicated, there is very good agreement for both eigenvalue and control rod positions with the maximum difference in eigenvalue of less than $400 \mathrm{pcm}$. The experimental data also include the 
control rod worth for CZP. The calculated results of MPACT and KENO are compared against the experimental results in Fig. 22, and good agreement is observed between the experimental and the MPACT and KENO results. Error bars representing $\pm 1 \sigma$ (standard deviation) are included in the KENO plot.

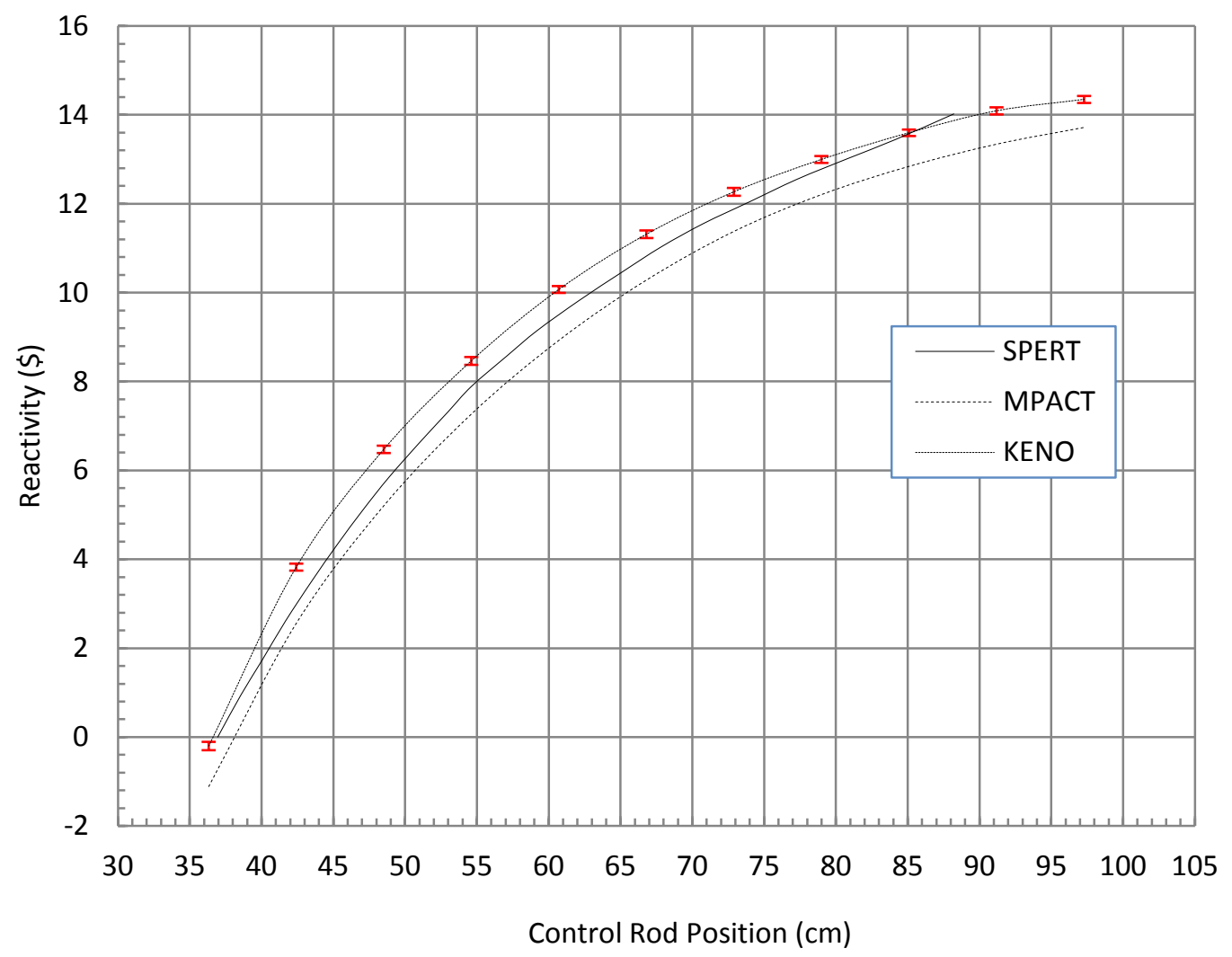

Fig. 22: Comparison of control rod worth for CZP

The experimental results do not include information on the power distribution and therefore the fission rate distributions were compared only between MPACT and KENO. Figures 23 and 24 show the comparison of the relative fission rate distributions between two codes at CZP and HZP, respectively. Among those figures, plot (a) includes the assembly-averaged fission rate distribution at the plane with the peak power (a quarter core); plot (b) includes the assembly-averaged fission rate distribution at the plane with the maximum difference (a quarter core); plot (c) includes the pin-wise relative difference distribution between two codes at the plane with the peak power (full core) and plot (d) includes the pin-wise relative difference distribution between two codes at the plane with the maximum difference (full core). Due to the rotational symmetry of the core, only the comparisons for a quarter core are presented in plots (a) and (b).

In the CZP peak-power plane, MPACT systematically underestimates the assembly plane-averaged power by 2.7 to $5.2 \%$ relative to KENO, which is a difference of up to $5 \sigma$ based on the KENO uncertainty. However, the overall shape of the power distribution shows excellent agreement between the two codes. The maximum relative difference of $6.5 \%$ occurs in the corner pin location of one of the 4 central assemblies, the same location as the peak pin power. In general, the relative difference between MPACT and KENO shows a strong correlation to the actual pin 
powers. The notable exception to this is the extreme corners of the core, where some minor geometry discrepancies (see the discussion in the HZP section) may come into play.

\begin{tabular}{|c|c|c|c|}
\cline { 2 - 4 } KENO & $1.376 \pm 0.027$ & $1.688 \pm 0.030$ & $1.900 \pm 0.032$ \\
MPACT & 1.339 & 1.634 & 1.835 \\
Rel. Diff. & $2.7 \%$ & $3.2 \%$ & $3.4 \%$ \\
\hline $1.364 \pm 0.027$ & $1.967 \pm 0.032$ & $2.705 \pm 0.038$ & $3.013 \pm 0.040$ \\
1.327 & 1.893 & 2.584 & 2.874 \\
$2.7 \%$ & $3.8 \%$ & $4.5 \%$ & $4.6 \%$ \\
\hline $1.678 \pm 0.030$ & $2.849 \pm 0.039$ & $3.981 \pm 0.058$ & $4.135 \pm 0.047$ \\
1.624 & 2.718 & 3.785 & 3.927 \\
$3.2 \%$ & $4.6 \%$ & $4.9 \%$ & $5.0 \%$ \\
\hline $2.007 \pm 0.033$ & $3.447 \pm 0.054$ & $4.302 \pm 0.049$ & $5.241 \pm 0.067$ \\
1.933 & 3.283 & 4.083 & 4.968 \\
$3.7 \%$ & $4.8 \%$ & $5.1 \%$ & $5.2 \%$ \\
\hline
\end{tabular}

(a) Assembly-averaged fission rate distribution (Plane 5, peak-power plane)

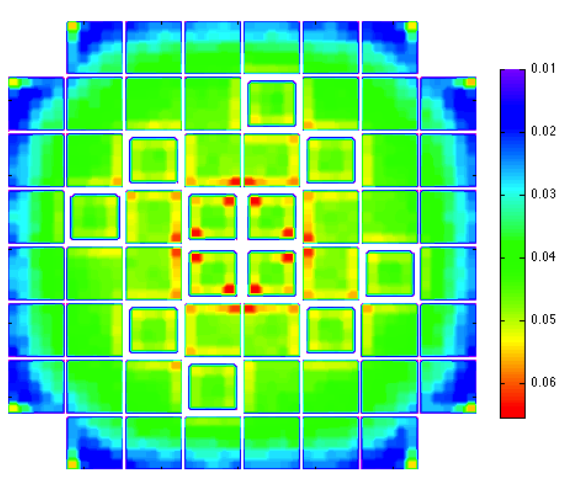

(c) Pin-wise relative difference of fission rate distribution (Plane 5, peak-power plane)

\begin{tabular}{|c|c|c|c|}
\hline KENO & $0.024 \pm 0.004$ & $0.026 \pm 0.004$ & $0.025 \pm 0.004$ \\
\hline MPACT & 0.029 & 0.032 & 0.03 \\
\hline Rel. Diff. & $-23.8 \%$ & $-24.2 \%$ & $-23.7 \%$ \\
\hline $0.022 \pm 0.003$ & $0.026 \pm 0.004$ & $0.028 \pm 0.004$ & $0.029 \pm 0.004$ \\
\hline 0.027 & 0.032 & 0.035 & 0.036 \\
\hline$-23.4 \%$ & $-22.6 \%$ & $-23.0 \%$ & $-22.8 \%$ \\
\hline $0.021 \pm 0.003$ & $0.022 \pm 0.004$ & & $0.042 \pm 0.005$ \\
\hline 0.026 & 0.027 & & 0.051 \\
\hline$-23.4 \%$ & $-21.9 \%$ & & $-22.7 \%$ \\
\hline $0.020 \pm 0.003$ & & $0.038 \pm 0.005$ & $0.065 \pm 0.008$ \\
\hline 0.025 & & 0.047 & 0.08 \\
\hline$-23.5 \%$ & & $-22.5 \%$ & $-22.9 \%$ \\
\hline
\end{tabular}

(b) Assembly-averaged fission rate distribution

(Plane 18, maximum-difference plane)

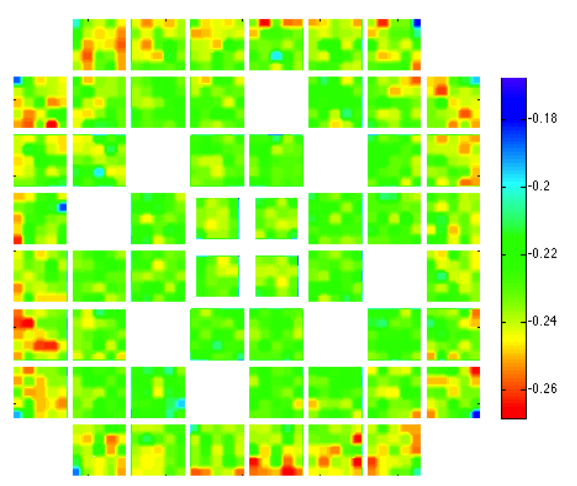

(d) Pin-wise relative difference of fission rate distribution (Plane 18, maximum-difference plane)

Fig. 23: Comparison of fission rate distributions for CZP configuration

In the CZP maximum difference plane, which is the topmost axial plane, MPACT systematically overestimates the assembly plane-averaged power by 21.9 to $24.2 \%$ relative to KENO, which is less than $2 \sigma$ based on the KENO uncertainty. Again, the overall shape of the power distribution shows excellent agreement between the two codes. The maximum relative difference of $26.8 \%$ is observed in the $[3,4]$ assembly. However, there is no correlation between pin power and relative pin power difference in maximum difference plane. All relative differences in this plane lie between $17.8 \%$ and $26.8 \%$ with an essentially random distribution. All relative pin powers in this plane are less than 0.1 for both KENO and MPACT. 


\begin{tabular}{|c|c|c|c|}
\hline KENO & $0.867 \pm 0.021$ & $0.978 \pm 0.022$ & $1.108 \pm 0.024$ \\
\hline MPACT & 0.862 & 0.975 & 1.103 \\
\hline Rel. Diff. & $0.6 \%$ & $0.3 \%$ & $0.5 \%$ \\
\hline $0.868 \pm 0.021$ & $1.043 \pm 0.023$ & $1.410 \pm 0.027$ & $1.572 \pm 0.028$ \\
\hline 0.863 & 1.040 & 1.398 & 1.556 \\
\hline $0.5 \%$ & $0.4 \%$ & $0.8 \%$ & $1.0 \%$ \\
\hline $1.000 \pm 0.022$ & $1.537 \pm 0.028$ & $2.354 \pm 0.045$ & $2.198 \pm 0.034$ \\
\hline 0.997 & 1.521 & 2.317 & 2.165 \\
\hline $0.3 \%$ & $1.0 \%$ & $1.6 \%$ & $1.5 \%$ \\
\hline $1.197 \pm 0.025$ & $2.050 \pm 0.042$ & $2.315 \pm 0.035$ & $3.185 \pm 0.052$ \\
\hline 1.190 & 2.020 & 2.278 & 3.114 \\
\hline $0.6 \%$ & $1.5 \%$ & $1.6 \%$ & $2.2 \%$ \\
\hline
\end{tabular}

(a) Assembly-averaged fission rate distribution (Plane 8, peak-power plane)

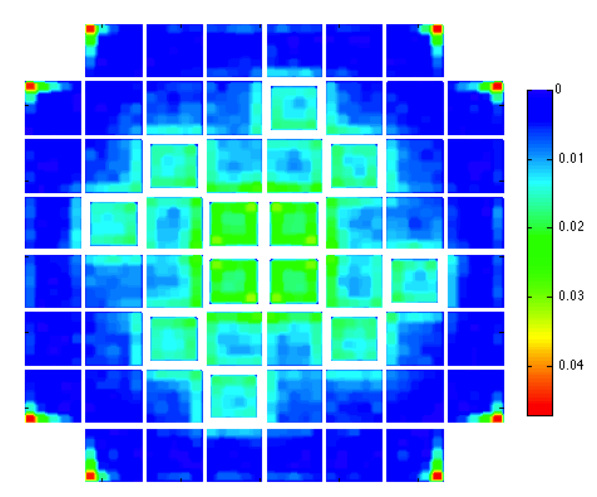

(c) Pin-wise relative difference of fission rate distribution (Plane 8, peak-power plane)

\begin{tabular}{|c|c|c|c|}
\hline KENO & $0.082 \pm 0.006$ & $0.085 \pm 0.007$ & $0.083 \pm 0.006$ \\
\hline MPACT & 0.092 & 0.096 & 0.094 \\
\hline Rel. Diff. & $-12.4 \%$ & $-13.5 \%$ & $-13.5 \%$ \\
\hline $0.078 \pm 0.006$ & $0.079 \pm 0.006$ & $0.083 \pm 0.007$ & $0.086 \pm 0.007$ \\
\hline 0.088 & 0.090 & 0.094 & 0.097 \\
\hline$-12.5 \%$ & $-13.2 \%$ & $-13.3 \%$ & $-13.4 \%$ \\
\hline $0.074 \pm 0.006$ & $0.067 \pm 0.006$ & & $0.119 \pm 0.008$ \\
\hline 0.084 & 0.076 & & 0.135 \\
\hline$-13.7 \%$ & $-13.2 \%$ & & $-13.2 \%$ \\
\hline $0.071 \pm 0.006$ & & $0.110 \pm 0.008$ & $0.185 \pm 0.012$ \\
\hline 0.081 & & 0.125 & 0.209 \\
\hline$-13.8 \%$ & & $-13.2 \%$ & $-13.0 \%$ \\
\hline
\end{tabular}

(b) Assembly-averaged fission rate distribution

(Plane 18, maximum-difference plane)

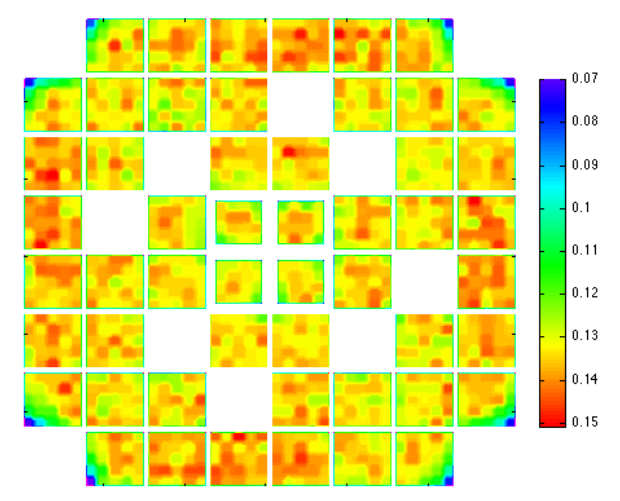

(d) Pin-wise relative difference of fission rate distribution (Plane 18, maximum-difference plane)

Fig. 24: Relative difference of fission rate distributions for HZP configuration

In the HZP peak-power plane, MPACT systematically underestimates the assembly plane-averaged power by up to $2.2 \%$ relative to KENO, which is a difference of less than $2 \sigma$ based on the KENO uncertainty. In fact, only the difference in the four central assemblies exceeds $1 \sigma$. Once again, the overall shape of the power distribution shows excellent agreement between the two codes. The maximum relative difference of $4.7 \%$ occurs in the outermost corners of the core, where pin powers are less than a third of peak power. This is likely due to inherent modeling differences between MPACT and KENO. In particular, MPACT is not capable of explicitly modeling the cylindrical core skirt and reflector, so it is discretized on the rectangular mesh whereas KENO can explicitly model the cylindrical geometry. Additionally, the KENO model includes small gaps between the walls of the filler pieces and the skirt/reflector region to avoid overlapping holes. Both of these minor discrepancies would have their largest effect at the corners of the core since that is the area closest to the skirt/reflector region. These anomalies aside, the relative difference between MPACT and KENO pin powers increases with pin power, showing a 
strong correlation. The maximum relative difference of $3.2 \%$ (ignoring the corner anomalies) is obtained in the corner pin location in one of the 4 central assemblies, where power is near peak.

In the HZP maximum difference plane, which is again the topmost axial plane, MPACT systematically overestimates the assembly plane-averaged power by 12.4 to $13.8 \%$ relative to KENO, which is less than $2 \sigma$ based on the KENO uncertainty. Yet again, the overall shape of the power distribution shoes excellent agreement between the two codes. The maximum relative difference of $15.1 \%$ is observed in the [4,1] assembly. However, there is no correlation between pin power and relative pin power difference in the maximum difference plane. All relative differences in this plane lie between $11.7 \%$ and $15.1 \%$ with an essentially random distribution, with the exception of the extreme corners due modeling discrepancies that have already been explained. (Note that effect is a decrease from the KENO pin power to the MPACT pin power, so for this plane in which the MPACT powers are higher than KENO, it reduces the relative difference between the two codes.) All pin powers in this plane are less than 0.25 for both KENO and MPACT.

Since both codes predict that the pin-wise peak powers are located in the center assemblies, the pin-wise fission rate distributions are numerically compared for the assembly with the peak power in Fig. 25. It can be seen that the maximum difference is less than $6.5 \%$ for CZP and $3.2 \%$ for HZP. The relative axial distributions of fission rate of this peak-power assembly are compared in Fig. 26 with error bars indicating $\pm 1 \sigma$ added to KENO plot, where good agreement can be observed for both CZP and HZP cases. Most of the MPACT and KENO pin powers shown in Fig. 25. are within $\pm 1 \sigma$ of the KENO uncertainties. In fact, the relative difference between the KENO and MPACT pin powers for HZP are all well within $1 \sigma$, while a few relative differences between the KENO and MPACT pin powers for CZP exceed $1 \sigma$, but are within $1.5 \sigma$.

\begin{tabular}{|c|c|c|c|}
\hline $5.898 \pm 0.283$ & $5.281 \pm 0.275$ & $5.306 \pm 0.271$ & $6.008 \pm 0.288$ \\
5.578 & 5.012 & 5.029 & 5.616 \\
$-5.4 \%$ & $-5.1 \%$ & $-5.2 \%$ & $-6.5 \%$ \\
\hline $5.281 \pm 0.275$ & $4.557 \pm 0.246$ & $4.567 \pm 0.251$ & $5.235 \pm 0.267$ \\
5.01 & 4.353 & 4.358 & 4.965 \\
$-5.1 \%$ & $-4.5 \%$ & $-4.6 \%$ & $-5.2 \%$ \\
\hline $5.306 \pm 0.276$ & $4.568 \pm 0.251$ & $4.549 \pm 0.250$ & $5.185 \pm 0.264$ \\
5.027 & 4.357 & 4.347 & 4.93 \\
$-5.3 \%$ & $-4.6 \%$ & $-4.4 \%$ & $-4.9 \%$ \\
\hline $5.998 \pm 0.288$ & $5.235 \pm 0.267$ & $5.185 \pm 0.264$ & $5.692 \pm 0.279$ \\
5.615 & 4.964 & 4.929 & 5.403 \\
$-6.4 \%$ & $-5.2 \%$ & $-4.9 \%$ & $-5.1 \%$ \\
\hline
\end{tabular}

(a) CZP

\begin{tabular}{|c|c|c|c|c|}
\cline { 2 - 5 } KENO & $3.321 \pm 0.213$ & $3.117 \pm 0.206$ & $3.151 \pm 0.208$ & $3.466 \pm 0.222$ \\
RPACT & 3.244 & 3.0502 & 3.0801 & 3.3559 \\
& $-2.3 \%$ & $-2.1 \%$ & $-2.3 \%$ & $-3.2 \%$ \\
\cline { 2 - 5 } Rel. Diff. & $3.111 \pm 0.208$ & $2.874 \pm 0.198$ & $2.912 \pm 0.192$ & $3.242 \pm 0.214$ \\
3.0514 & 2.8257 & 2.8593 & 3.1657 \\
$-1.9 \%$ & $-1.7 \%$ & $-1.8 \%$ & $-2.4 \%$ \\
\cline { 2 - 5 } & $3.151 \pm 0.211$ & $2.911 \pm 0.204$ & $2.944 \pm 0.203$ & $3.266 \pm 0.209$ \\
3.0815 & 2.8596 & 2.8931 & 3.1952 \\
$-2.2 \%$ & $-1.8 \%$ & $-1.7 \%$ & $-2.2 \%$ \\
\hline $3.460 \pm 0.218$ & $3.242 \pm 0.207$ & $3.262 \pm 0.215$ & $3.527 \pm 0.219$ \\
3.3567 & 3.1659 & 3.1953 & 3.447 \\
& $-3.0 \%$ & $-2.3 \%$ & $-2.0 \%$ & $-2.3 \%$ \\
\hline
\end{tabular}

(b) HZP

Fig. 25: Comparison of pin-wise fission rates of the peak power assemblies 


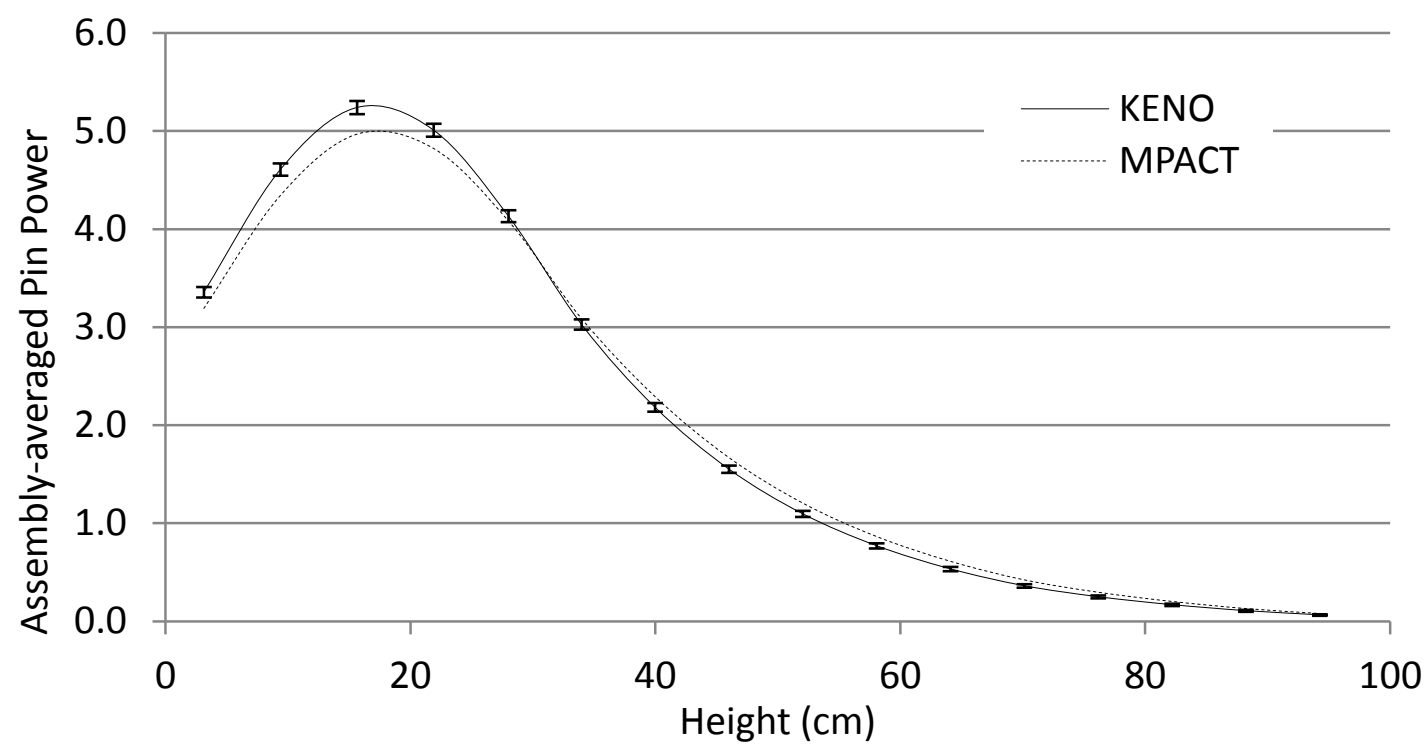

(a) CZP

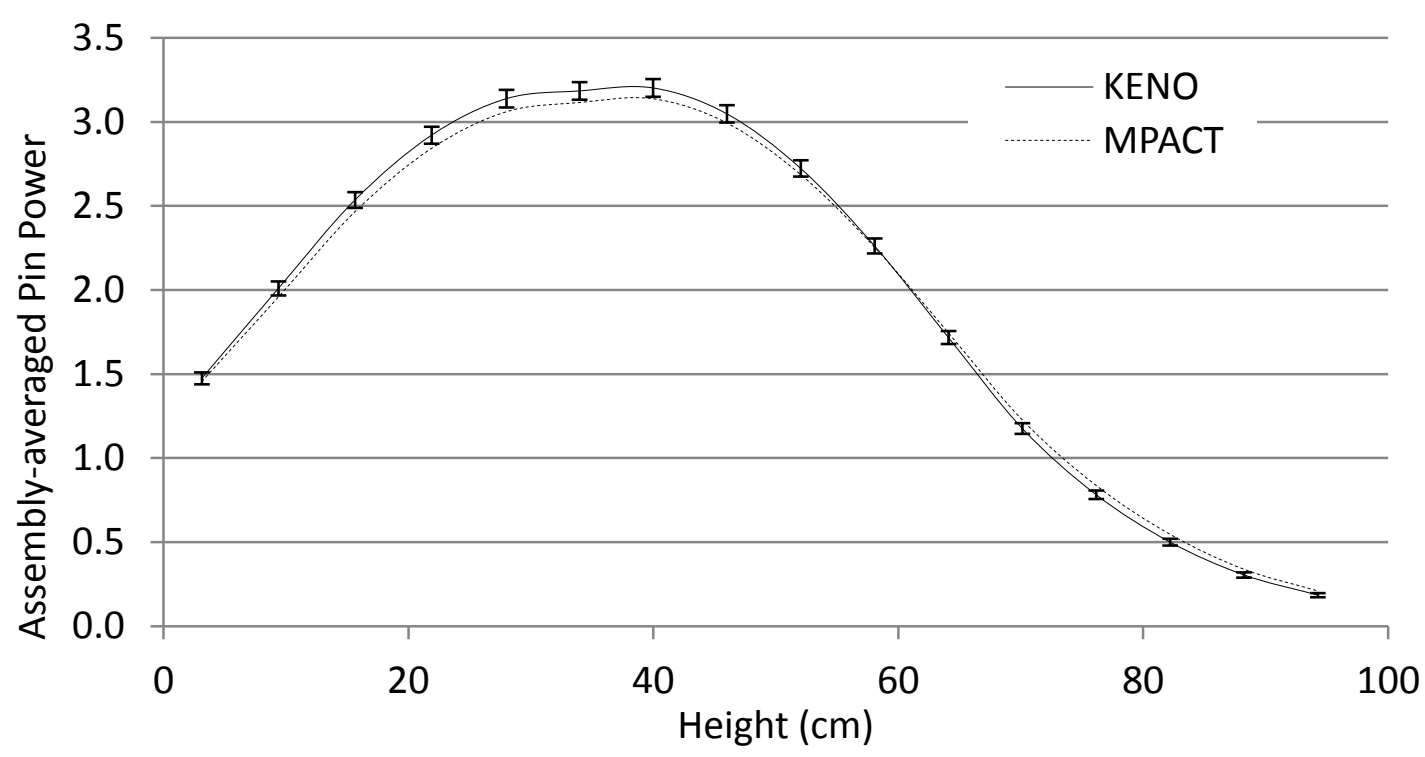

(b) HZP

Fig. 26: Axial fission rates distribution

Overall, KENO and MPACT have the same magnitude of discrepancies in both eigenvalues and control rod worth against the experimental data. Although in some cases a large discrepancy was observed in the fission rate distribution between KENO and MPACT, most of them are found in the regions with very low relative power. Because the comparisons are made based on the 3D pin-wise relative fission rates of the SPERT III E-Core with a very bumpy flux distribution, the relatively large discrepancies in the very low-power regions are acceptable. Another observation is that all comparisons show better agreements for HZP condition than CZP condition for both codes. This indicates there may be some possibility for further improvements on the nuclear data library.

\section{Summary and Conclusions}


In order to establish a benchmark model for three-dimensional heterogeneous core simulations with complex geometry and composition, a detailed steady-state neutronics model for SPERT III E-Core was developed using the Monte Carlo code KENO and the deterministic code MPACT. All in-core components including grid spacers, end-plugs, filler assemblies and flux suppressors are explicitly modeled. Numerical results show relatively good agreement with the measurements at both CZP and HZP cases. The discrepancies in $\mathrm{k}_{\text {eff }}$ are within $200 \mathrm{pcm}$ for KENO and $400 \mathrm{pcm}$ for MPACT at both CZP and HZP states. The fission rate distributions at both cases are also compared between KENO and MPACT.

The above observations support the following conclusions:

1) The detailed three-dimensional heterogeneous modeling of complex reactor is feasible for both the deterministic code MPACT and the Monte Carlo code KENO.

2) Detailed geometry descriptions of in-core components are very important for steady-state validation.

3) The SPERT III E-Core experiment can be used as a benchmark for high-fidelity simulations of light water reactors.

4) Both KENO and MPACT can provide good results for the $\mathrm{k}_{\text {eff }}$ of both CZP and HZP cases. The fission rates distribution agrees well between KENO and MPACT except in some regions with very low relative power.

The confidence developed in the ability to predict the steady-state condition of the SPERT III E-core provides the necessary condition for future work to perform a sequence of SPERT transient simulations with the MPACT code.

\section{Acknowledgement}

This research was supported by the University of Michigan and the Consortium for Advanced Simulation of Light Water Reactors (www.casl.gov), an Energy Innovation Hub (http://www.energy.gov/hubs) for Modeling and Simulation of Nuclear Reactors under U.S. Department of Energy Contract No. DE-AC05-00OR 22725.

\section{References}

Aoki, S., Suemura, T., Ogawa, J., et. al., 2009. Analysis of the SPERT III E-core using ANCK code with the chord weighting method, Journal of Nuclear Science and Technology, Vol. 46(3).

Bowman, S. M., 2011. SCALE 6: Comprehensive Nuclear Safety Analysis Code System, Nucl. Technol. 174(2), 126-148.

Durgone, J., 1965. SPERT III Reactor Facility: E-CORE Revision, p. 18, AEC Research and Development Report IDO-17036.

Grandi, G., Moberg, L., 2012. Qualification of CASMO5/SIMULATE-3K against the SPERT III E-Core Cold Start-up Experiments, PHYSOR 2012, Knoxville, Tennessee, USA. 
Grandi, G., 2014. Validation of CASMO5/SIMULATE-3K Using the Special Power Excursion Test Reactor III E-CORE: Cold Start-up, Hot Start-up, Hot Standby and Full Power Conditions, PHYSOR 2014, Kyoto, Japan.

Kochunas, B., Collins, B., Jabaay, D., et. al., 2013. Overview of Development and Design of MPACT: Michigan Parallel Characteristics Transport Code, Proc. M\&C 2013, Sun Valley, ID, USA.

Kosaka, I., Kawata, N., Wakabayashi, T., 1988. Verification of the EUREKA-ATR code, Analysis of the SPERT III E-Core Experiment, PNC SN 9410 88-057.

Liu, Y., Collins, B., Kochunas B., et al. Resonance Self-shielding Methodology in MPACT. In Proc. M\&C 2013, Sun Valley, ID, USA, May 5-9 2013.

McCardell, R.K., Herborn, D.I., Houghtaling, J.E., 1969. Reactivity Accident Test Results And Analysis for the SPERT III E-Core - A Small Oxide-Fueled, Pressurized-Water Reactor, p. 15, AEC Research and Development Report IDO-17281.

Olson, A.P., 2013. Neutronics Calculations for SPERT-III, E-Core. ANL/GTRI/TM-13/10, 2013, DOI: $10.2172 / 1087815$

Wang, R.C., Xu, Y., Hudson, N., et. al., 2013. Validation of the U.S. NRC Coupled Code System TRITON/TRACE/PARCS Using the Special Power Excursion Reactor Test III, Nuclear Technology, Vol. 183(3): 504-514.

Yamaji, K., Takemoto, Y., Kirimura, K., et. al., 2014. Validation of the Nodal Kinetics Code System GALAXY/COSMO-K Using the SPERT-III E-CORE Experiments, PHYSOR 2014, Kyoto, Japan. 